\title{
Los cárteles no existen: Narcotráfico y cultura en México.
}

Reseña / Review: Oswaldo Zavala, Los carteles no existen: Narcotráfico y cultura en México. México. Malpaso, 2018. 283 pp.

Enrique Chacón Southern Oregon University chaconl@sou.edu

[ n diciembre de 2006 Felipe Calderón inició la guerra contra el narco en - México y aún no sabemos bien las dimensiones de todo lo que ocurrió. Los efectos económicos, sociales y culturales que está teniendo en la población aún no pueden ser cuantificados. Dentro de esta incertidumbre aparece el libro Los cárteles no existen de Oswaldo Zavala. Este libro intenta, y hasta cierto punto consigue, encontrar una pausa al repetitivo ruido que nos ofrecen la violencia social asociada al narcotráfico y los discursos y representaciones entorno a ella que encontramos en los medios de comunicación mexicanos.

El libro de Zavala se desenvuelve entre lo académico y lo periodístico, en sus 
páginas nos expone a una investigación fresca y actualizada sobre los eventos más recientes. El interés público y académico y la novedad del tratamiento que del tema propone Zavala son al mismo tiempo su contribución principal y uno de sus retos centrales: un tema tan complejo requiere detenida reflexión, investigación de campo, y un robusto apoyo teórico. A pesar de ello, Zavala resuelve estos retos con numerosos ejemplos que provienen tanto de fuentes periodísticas como de la producción teórica y cultural reciente.

En un ejercicio de muy fino hilado, Zavala explica valientemente su teoría -casi conspirativa, como él mismo sugiere- en la que desmitifica a las figuras de poder que se identifican con los cárteles, al igual que pone en entredicho la existencia de los cárteles como organizaciones estables.

Queda claro que la violencia y los problemas tienen nombres y rostros, como el de El Chapo Guzmán por ejemplo, pero según Zavala, esta capacidad que tenemos de señalar personas específicas, es más bien un mal necesario del que se aprovecha la dinámica transnacional del tráfico y consumo de estupefacientes. Los cárteles como tal, son un invento discursivo, según Los cárteles lo aclara al final de la Introducción:

El "narco" en México y Estados Unidos funciona como ese inteligente y perverso ardid de Tony Soprano. El "narco" aparece en nuestra sociedad como una temible caja de Pandora que, de ser abierta, creemos que desataría un reino de muerte y destrucción. Si pudiéramos vencer el miedo y confrontar aquello que llamamos "narco" abriendo por fin la caja, no encontraríamos en ella a un violento traficante, sino al lenguaje oficial que lo inventa: escucharíamos palabras sin objeto, tan frágiles y maleables como la arena. (Kindle, Location 229)

De esta manera, lo que hemos percibido como el peligro que los cárteles generan, se aparece como una fabulación que se desarrolla por medios más o menos artificiales: el Chapo, por nombrar a alguno, es el rostro de un 
problema más profundo en el que ni siquiera él mismo tendría una injerencia fundamental; es decir, que las complejidades de un mercado de drogas voraz, las políticas internacionales, el mercado legal e ilegal de armas, el flujo monetario en donde todo se vuelve un solo capital, difícilmente pueden ser controladas por un solo criminal cuya virtud mayor sería la de ejercer la violencia.

En ambos lados de la frontera entre México y Estados Unidos, se generan productos culturales que condicionan nuestra percepción de estos fenómenos. Zavala estudia como un continuum cultural los discursos políticos, la producción de noticias, las producciones de series y de películas, así que fija su atención en la manera en la que se simbolizan y mitifican las figuras del narco para el consumo del público de Estados Unidos, siempre diferenciadas de las representaciones que se realizan en México.

En ambos países y en todos los casos, los medios siempre han de tomar información e inspiración en la fuente fundamental: el documento oficial, desde donde se nutre lo que ellos defienden con convicción de que representan la "realidad". La llamada de atención propone no perder de vista que la mayoría de las representaciones que conocemos y la realidad, están separadas por una "densa estructura de significado" que según Zavala, vuelve difícil comprender la esencia de la los fenómenos.

En buena medida esto compone el centro de su argumento; lo que los gobiernos y los medios presentan como generador de la violencia, es una invención discursiva que no concuerda con la realidad verificable. Los cárteles, según Zavala, son un elemento [ficticio?] de una narrativa transnacional, los cuales justifican la implementación de medidas económicas y de seguridad con la finalidad de controlar políticamente a las sociedades involucradas: Estados Unidos y México. Este control tiene como objetivo infundir el miedo en la población mexicana para poder explotar de manera libre sus recursos naturales, mientras que a la vez se intenta presentar a México como una región 
peligrosa a la población de Estados Unidos para justificar la intervención y la inversión en una interminable Guerra contra las drogas.

En esta descripción que Zavala hace del panorama de la violencia, se inserta la controvertida reforma energética que México hizo durante el sexenio anterior y la aparición de Trump en el panorama internacional y el trato humillante hacia Enrique Peña Nieto desde sus primeras interacciones. Así, lo que como público percibimos como la violencia y las medidas para prevenirla o reprimirla son, según Zavala, un fruto del neoliberalismo dentro de una lógica actualizada de la Guerra Fría.

Tras evaluar este panorama político y económico, Zavala pasa a revisar algunos productos artísticos y culturales, sobre los cuales aporta un análisis que se compone de dos grupos, en ambos casos parece que este análisis perdió de vista algunos detalles. No quedan del todo claros los argumentos por los que Zavala califica y descalifica la obra de Margolles como la "condensación simbólica de la mitología del narco", puesto que pierde de vista que Margolles trabajó temas funestos desde los años 90 cuando colaboraba con SEMEFO y tal vez como tema, sea una continuación de sus intereses estéticos.

El análisis de estos artistas mexicanos parece un poco esencialista, parece que la valoración que realiza Zavala está enfocada a censurar o aprobar la producción artística, por una parte, él encuentra ciertos artistas cuya obra está mediada totalmente por el discurso oficial de poder, mientras que hay otros que son profundamente críticos con este poder y pueden desvelar con claridad los mecanismos perversos de su narrativa. César López Cuadras, Daniel Sada, Roberto Bolaño, y Juan Villoro son ejemplos de las voces que resultan críticas. Si bien explica particularidades de cada caso y la manera en la que recusan, denuncian, problematizan y señalan los problemas de la violencia causados por los fantasmagóricos cárteles y el estado, no queda tan claro que esto se cumpla de manera total. En su análisis de 2666 Zavala concluye que Bolaño "explora tangencialmente el fenómeno" (Kindle Location 2641) del narco, 
termina por explicarlo de manera "magistral", confirmando la imposibilidad de mostrar de manera objetiva la violenta realidad transnacional del narcotráfico.

Por otra parte, en el caso de estos cuatro escritores que comenta al igual que en el de Margolles, este autor nos lleva a repensarlos y a reconsiderarlos bajo este nuevo prisma. A pesar de que respecto a la producción cultural es radical en su lectura, Zavala acierta al proponer distintas maneras de generar una reflexión crítica. Los cárteles no existen hace una detenida lectura de la representación de la frontera y los espacios que sufren de manera más directa los efectos de la violencia, repasa las voces más críticas con la finalidad de revelar ese mecanismo público según el cual toda la violencia de la Guerra contra el Narco proviene de los cárteles. Como Zavala nos recuerda, y como lo refieren muchas fuentes, esta violencia viene con frecuencia de los mecanismos de seguridad estatales enfocados en la lucha contra el narco.

La importancia, el valor de este libro, radica precisamente en su capacidad de análisis y de problematización de esta guerra, la variedad de ejemplos que pone a consideración del lector hace que el diálogo con este libro se genere de una manera fluida por la cantidad de estímulos que lanza al lector. Es necesario relacionarse con estas páginas, reñir con ellas, estar de acuerdo y en desacuerdo, estos modos de lectura siempre deben ser bienvenidos en el debate académico, el mismo autor lo reconoce así: este libro es una invitación para que reflexionemos de manera detenida sobre estos procesos y fenómenos. Y esta es una actividad tan necesaria como el importante libro de Oswaldo Zavala.

Epílogo sobre el nuevo epílogo:

Después de que Andrés Manuel López Obrador asumiera la presidencia aparece una reedición (la cuarta) de Los cárteles no existen con un nuevo epílogo. En este añadido, Zavala señala los cambios en el discurso del poder 
que existen entre los gobiernos anteriores y el de AMLO. Según Zavala, los cambios en la narrativa para enfrentar a los fantasmagóricos cárteles son sustanciales porque el nuevo presidente intenta lograr la paz, no la guerra. Esto marca una nueva aproximación a la violencia, a los problemas del tráfico de drogas y a los asuntos de seguridad nacional.

El nuevo presidente ha decidido poner más atención a lo que él identifica como uno de los principales problemas de México: el del robo de hidrocarburos. En esto parece haber una organización meticulosa entre empleados mismos de la empresa Petróleos Mexicanos y "delincuentes" externos. A este tipo de robo en México se le llama "huachicol". Este es el nombre que maneja el gobierno y los medios ahora han empezado a hablar de la "guerra contra el huachicol", retomando así en cierta medida la narrativa de la guerra contra el narco. Zavala identifica en las políticas de AMLO ciertos intentos emancipadores o al menos cierto distanciamiento en la relación con Estados Unidos. Esto también se ve en la cancelación del Centro de Investigación y Seguridad Nacional, cuyos archivos secretos serán publicados en breve.

Zavala termina su texto con varias preguntas y una reflexión. Las primeras, sin duda serán el centro de la crítica al nuevo gobierno y están enfocadas a reflexionar sobre la capacidad del nuevo gobierno para ser incluyente, porque según su reflexión, la inclusión de toda la sociedad en las políticas de gobierno puede ser la solución para los terribles problemas que el país enfrenta. 